\title{
Construcción decapital social en barrios vulnerables: un desafío emergente para la política habitacional
}

\author{
Jenny Moreno Romero* \\ Jeanne W. Simon**
}

\section{RESUMEN}

El presente artículo tiene como objetivo analizar los desafíos de la política habitacional chilena, en torno a la generación de capital social en barrios vulnerables. Se plantea la necesidad de complementar los actuales sistemas de evaluación y diseño de las políticas urbanas y habitacionales, desde el enfoque integral del capital social

Palabras clave: Capital social- barrios - política social - política habitacional.

Construção de capital social em bairros vulneráveis: Um desafio emergente para a política habitacional

\section{RESUMO}

O presente artigo tem como objetivo analisar os desafios da política habitacional chilena, em torno da geração de capital social em bairros vulneráveis. Propõe-se a necessidade de complementar os atuais sistemas de avaliação e desenho das políticas urbanas e habitacionais, desde o enfoque integral do capital social

Palavras chave: Capital social - bairros - política social - política habitacional.

Building social capital in disadvantaged neighborhoods: An emerging challenge for housing policy

\section{ABSTRACT}

This article aims to analyze the challenges of the Chilean housing policy around the creation of social capital in disadvantaged neighborhoods. It expresses the need to supplement current systems of evaluation and design of urban and housing policies from the comprehensive approach of social capital.

Key Words: Social capital - neighborhoods - social policy - housing policy

* Chilena. Trabajadora Social y Licenciada en Trabajo Social. Colaboradora Académica Departamento de Trabajo Social, Universidad de Concepción. Correo electrónico: jenmoreno@udec.cl

** Estadounidense. Licenciada en Ciencia Política. Magíster y Doctora en Estudios Internacionales. Directora Magíster en Política y Gobierno Universidad de Concepción. Correo electrónico: jsimon@udec.cl 


\section{Antecedentes}

En Chile la política urbana que se definió para el período 20062010, se basó en lineamientos estratégicos tendientes a lograr más integración social y acceso equitativo a todos los sectores urbanos, mediante la recuperación de los espacios públicos, descentralización y participación ciudadana, a través de planes y obras urbanas concertadas con vecinos, municipios y regiones.

Lo anterior, se enmarca en el desafío asumido por parte del Ministerio de Vivienda y Urbanismo (MINVU). orientado a reemplazar una política tradicional, centrada en reducir el déficit habitacional, a una enfocada a la construcción de barrios, con un fuerte énfasis en la integración social.

Los ejes claves a los que apunta esta política habitacional, reflejan la necesidad de replantear los actuales sistemas de evaluación del MINVU y fortalecer la medición de resultados a partir de un enfoque integral basado en el Capital Social, que avanza hacia la comprensión de aquellos atributos de las comunidades que les permiten generar procesos sustentables de desarrollo al facilitar acciones de cooperación mutua.

De esta forma, a partir de la perspectiva del capital social se puede estimar la efectividad de los programas sociales, con el fin de extraer aprendizajes significativos que orienten el proceso de planificación de los programas habitacionales en el país, especialmente si se considera que los agentes de políticas públicas han comenzado a considerar el capital social como un activo que ayuda a los individuos a superar la pobreza.

Desde esta óptica, a partir del análisis del capital social en las políticas habitacionales, se puede aportar a la consolidación de políticas sociales integrales que entreguen sustentabilidad a la construcción de barrios y ciudades en el país y a superar algunos nudos críticos que se observan actualmente en torno al diseño y evaluación de programas habitacionales.

Esto cobra particular relevancia en el actual contexto post terremoto que vivencia Chile, pues las políticas de vivienda representan un área prioritaria, que requieren el diseño de programas que contribuyan al objetivo de superación de la pobreza y al desarrollo con equidad, lo que necesariamente se vincula con el mejoramiento de la calidad de vida de los barrios. Por ende, la incorporación de los componentes del capital social 
se visualiza como activos que aportan a este objetivo y a los procesos de integración social del país.

\section{Capital social y reforma de las políticas sociales}

En América Latina se ha puesto en marcha una segunda ola de reformas de las políticas sociales, caracterizada por una mayor participación de la sociedad civil en el diseño, la gestión y la rendición de cuentas de los proyectos y programas públicos, lo que otorga un mayor papel a los beneficiarios frente al Estado y a la empresa privada.

Durston (2002) señala que el eje central de esta reforma del Estado es el empoderamiento de los actores sociales en los diversos niveles territoriales, que pone nuevamente en la agenda pública las cuestiones éticas de la equidad social y la participación democrática, sin descuidar por ello la eficiencia en el uso de los recursos públicos. Esta transformación en ciernes de la política social, se centra en la propuesta de fomentar una nueva sinergia entre el Estado y el capital social comunitario.

Las reformas se basan en algunos supuestos clave, entre los cuales se cuenta, como condición necesaria, la capacidad de los integrantes de los grupos sociales y las comunidades de cooperar entre sí, en una gestión colectiva, coordinada con el apoyo externo. Se supone, entonces, que existe un capital social, a partir del cual la capacitación y la práctica podrán fortalecer la participación de la comunidad en la ejecución de estos nuevos programas. Otro supuesto clave es que haya una reforma real del Estado, que apunte a transformar los sistemas de clientelismo autoritario, partidario o paternalista, para constituir un sistema de servicio al público, de empoderamiento de los sectores débiles de la sociedad civil, y de rendición de cuentas de los servidores públicos ante los usuarios que deben atender (Durston, 2002).

Chile no ha estado exento de estas transformaciones de la política social, pues a partir del año 1990, el Estado ha asumido un rol integrador, con la puesta en marcha de una política social promocional, complementaria a la económica, orientada preferentemente a los sectores pobres y más postergados, y caracterizada por dar prioridad a la calidad de los servicios. La equidad en los resultados, la inversión en capital social y el desarrollo productivo se han constituido en ejes centrales de esta 
política, abriendo canales de participación social que privilegian la expansión de capacidades, la transferencia de herramientas y ampliación de las posibilidades de acción autónoma de los sectores pobres para, en interdependencia con otros, incorporarse al proceso de desarrollo nacional.

Este cambio de paradigma en la política social, asociado a la Reforma del Estado, permitió la transición de una visión de la población como beneficiario/a y receptor de programas, a una en la cual la población es sujeto y ciudadano con derechos, deberes y responsabilidades personales o colectivas. Esto se vincula a la promoción de capacidades para que las personas, familias y comunidades desarrollen desde sí mismos iniciativas para mejorar la calidad de vida, siendo partícipes en la definición y búsqueda de solución a sus problemas. Para ello, resulta necesario vincular los sectores pobres y vulnerables con una red de apoyo y asistencia técnica con la cual puedan conversar y negociar apoyos para sus propias iniciativas de mejoramiento de calidad de vida (Raczynski, 2002).

\section{Políticas habitacionales: Reorientando los sistemas de evaluación y diseño de programas}

El Ministerio de Vivienda y Urbanismo (MINVU), a partir de los años noventa, ha ido integrando paulatinamente la reforma de las políticas sociales a sus diversos programas sociales. A partir del diagnóstico del déficit habitacional y urbano acumulado, los gobiernos propusieron el diseño y ejecución participativa de los programas habitacionales, la construcción de más viviendas para los más pobres y allegados, y el reemplazo de una política de provisión de viviendas centrada en soluciones a la falta de vivienda o habitabilidad básica de sectores excluidos de la sociedad, por otra dirigida a construir barrios y ciudades.

Los éxitos productivos del sector habitacional, que situó a Chile como el primer país latinoamericano en reducir el déficit habitacional, impusieron estos nuevos desafíos, donde la inversión urbana en equipamiento e infraestructura, servicios y espacios públicos de calidad adquiere un mayor protagonismo, considerándose como elementos complementarios e indispensables de los sistemas de vivienda social. 
En este nuevo escenario se plantea la necesidad de "políticas habitacionales y urbanas que aseguren una mejor calidad de vida para la gente y sus barrios, que fomenten la integración y reduzcan la desigualdad", propósito que se concretó en el cuarto gobierno de la Concertación mediante la puesta en marcha de la "Política Habitacional de Mejoramiento de la Calidad e Integración Social".

Dicha política planteó como grandes desafíos: disminuir el déficit habitacional, focalizando en las familias que viven en pobreza; garantizar la calidad de las viviendas, mejorando su estándar y los procesos de diseño y construcción; y promover la integración social, procurando soluciones habitacionales insertas en barrios y ciudades (Brain, Cubillos y Sabatini, 2007).

Es así como surge la integración social de las familias a la ciudad, como el nuevo eje de la política habitacional chilena. Esto se justifica producto de la segregación residencial en que viven diversos barrios pobres ubicados en la periferia de las ciudades, con carencias de equipamientos y servicios que impiden satisfacer las necesidades de las familias, lo que genera un círculo vicioso de profundización de la pobreza y da lugar a la formación de guetos urbanos.

Lo anterior es un reflejo de cómo la política social chilena, y en específico, la política habitacional, ha ido incorporando paulatinamente principios como la participación ciudadana, empoderamiento y capital social dentro de sus diseños. Un ejemplo de esta política es el Programa de Recuperación de Barrios implementado por el Ministerio de Vivienda y Urbanismo en el año 2006. Sin embargo, pese a este gran avance, existen dificultades al momento de evaluar el impacto de estos nuevos componentes sociales, pues los actuales sistemas de medición resultan insuficientes para valorar los resultados de programas sociales, que han surgido bajo el efecto de la segunda ola de reformas de la política social en América Latina.

En el caso del Ministerio de Vivienda y Urbanismo, los actuales sistemas de medición están basados preferentemente en aspectos como la satisfacción usuaria, lo que no refleja en total magnitud el impacto de los nuevos principios sociales que guían estos programas. Por este motivo, resulta de interés proponer sistemas de evaluación alternativos, que integren estos nuevos componentes. Desde esta perspectiva, surge el enfoque del capital social, que se propone como modelo de evaluación y diseño de los programas sociales de vivienda y urbanismo. 
Lo anterior se justifica, porque el capital social constituye un concepto que ha cobrado relevancia en la discusión sobre fuerzas del progreso económico, desarrollo social, ciudadanía y equidad, y entre éstas los programas habitacionales (Arriagada y Sepúlveda, 2002).

Distintos autores han propuesto que, para efectos de programas sociales, el enfoque del capital social serviría tanto como herramienta o instrumento para un mejor diseño, como un indicador en sí mismo del resultado o efectividad.

Más aún, en lo referente a evaluación, se ha sostenido que las políticas sociales deberían evaluar su impacto sobre el capital social, de modo análogo a otros criterios de evaluación ya asumidos por la agencia pública, como por ejemplo los sistemas de evaluación de impacto ambiental (PNUD, 2000).

Esto resulta relevante, pues si bien es cierto, los componentes del capital social como la confianza, participación, redes sociales, entre otros, están integrados dentro del diseño de algunos programas de desarrollo urbano, el enfoque del capital social aún no está considerado explícitamente como criterio de efectividad. Esto resulta contradictorio, pues el capital social, se presume como un elemento que permite mayor poder de acción a las comunidades y propicia mayor eficacia de los programas públicos por la participación de los ciudadanos en la búsqueda de un mejor nivel de vida.

Los beneficios de integrar el enfoque del capital social en la implementación de la política social de tipo habitacional son múltiples, especialmente porque se favorece el desarrollo integral de los barrios, permitiéndoles alcanzar sus fines, ser autosustentables, y superar sus niveles de vulnerabilidad y exclusión social.

En la Conferencia Internacional "En busca de un nuevo paradigma: capital social y reducción de la pobreza en América Latina", organizado por la CEPAL y la Universidad de Michigan (2003), se reafirma lo mencionado anteriormente, ya que se concluye que la perspectiva del capital social ayuda a una evaluación más integral de los programas de vivienda, permitiendo mostrar aspectos de la gestión urbana que se relacionan a objetivos tanto de participación ciudadana, como de reforma urbana y superación de la pobreza. 
La participación en el diseño, ejecución y evaluación de presupuestos y proyectos, son ejemplos de cómo el capital social de los sectores pobres puede aportar tanto a la eficacia de los programas sociales, como también a la articulación de iniciativas intersectoriales y directamente a la producción de bienes públicos (World Bank, 2000). Las políticas habitacionales en Chile, han avanzado en esta línea, específicamente a partir del año 2006, ya que se han implementado programas que consideran la participación de la comunidad en todas sus etapas, de tal forma de proporcionar una mayor sustentabilidad a las obras físicas y cambios a desarrollar en el entorno.

\section{Una aproximación al enfoque del capital social}

A partir de la década del noventa el concepto de capital social ha sido utilizado extensivamente en las ciencias sociales, encontrando sus principales premisas fundacionales durante la década de 1980, donde encuentra su origen en el ámbito de la sociología económica. Desde esta época este concepto ha sido sometido a intensos debates respecto de su definición y por ende, de las dimensiones e indicadores adecuados para su análisis. De esta forma, podemos concebirlo como un paradigma inmaduro, un enfoque en construcción, pero además, una de las innovaciones más prometedoras de la teoría social contemporánea, formando parte de las herramientas analíticas de los especialistas en desarrollo social y económico, además de las formulaciones de organismos multilaterales y agencias de cooperación, en torno a su utilidad para la elaboración de políticas de inclusión orientadas a la solución de las problemáticas de América Latina.

Dentro de estas problemáticas ha adquirido relevancia en el debate sobre la superación de la pobreza, siendo considerado un factor explicativo de las posibilidades de equidad territorial, progreso económico, bienestar y ciudadanía. Se sostiene que el nuevo contexto económico-social está marcado por la emergencia de riesgos sociales, tales como posibilidades de marginación, empobrecimiento o exclusión; y que la capacidad de las comunidades para enfrentar momentos de crisis depende de los activos o recursos de los que disponen las personas. Junto con el trabajo, el capital financiero, el capital físico y patrimonial, y el capital humano (salud y educación), el capital social es un activo central (World Bank, 2001). 
Sugiriendo que el capital social es un factor que ayuda tanto al progreso económico, como a reducir conductas condescendientes con la inequidad, con respecto a la movilidad social, la existencia de capital social favorece una mejor educación y más oportunidades de empleo (Kaztman, 2001).

Al efectuar un recorrido por las principales contribuciones teóricas de autores que han trabajado este concepto, se rescatan los aportes de Putnam (1993) y Durston (1999), pues aluden a aquellas dimensiones e indicadores que resultan adecuados para analizar las políticas habitacionales desde la perspectiva del capital social.

Putnam (1993) considera que el capital social "está constituido por aquellos elementos de las organizaciones sociales, como las redes, las normas y la confianza, que facilitan la acción y la cooperación para beneficio mutuo" (Putnam 1993:14), pues, tal como plantea el autor, el trabajo en conjunto es más fácil en una comunidad que tiene un acervo abundante de capital social.

La obra de Putnam (1993) se centra en la comprensión de los problemas que presenta la acción colectiva, especialmente la tendencia comunitaria hacia la cooperación en pro del bien común o al oportunismo y los factores que condicionan la primera o la segunda elección, determinando de qué manera repercuten en el desarrollo económico y democrático-institucional de las comunidades (Forni, Siles y Barreiro, 2004).

Específicamente, las políticas habitacionales se relacionan más estrechamente con el capital social comunitario a las que Durston (1999) hace referencia como aquellas "normas, prácticas y relaciones interpersonales realmente existentes y observables, a nivel de comunidad o sistema social más amplio, que determinan cómo funciona en la práctica la organización social" (Durston 1999: 32).

De las contribuciones de estos autores y de otras investigaciones realizadas en América Latina, se desprenden ciertos componentes del capital social que pueden ser relevantes para el diseño y evaluación de programas habitacionales. Se trata de las relaciones de confianza, la función de las redes sociales, la cooperación de las comunidades, la participación social y la valoración local, que pueden constituir factores explicativos del porqué algunas comunidades alcanzan mayores niveles de desarrollo económico y democrático que otras. 


\section{Construcción de capital social: Una oportunidad para el desarrollo de barrios vulnerables}

El capital social comunitario manifestado en diferentes formas de asociatividad, es un elemento importante del empoderamiento (CEPAL, 2001). En este sentido, es importante señalar que los proyectos pueden fomentar el capital social, existiendo posibilidades concretas, a través de formas o partidas de presupuesto que incorporan participación y asociatividad (por ejemplo, infraestructura), que serviría para prevenir fallas de ingeniería social (Arriagada y Sepúlveda, 2002).

Si se asume la posición de que se puede construir capital social comunitario, la utilización de un marco basado en el concepto de capital social puede servir para enfocar una política pública, favoreciendo la participación efectiva de sectores sociales excluidos y de extrema pobreza. Esta construcción intencional del capital social puede llevar a mayores tasas de éxito en los programas de superación de la pobreza que incorporan elementos de autogestión y de fiscalización de servicios por parte de la sociedad civil (Durston, 2000).

De acuerdo a lo señalado anteriormente, el aporte de esta perspectiva a los sistemas de evaluación de los programas de vivienda resulta relevante, principalmente por la posibilidad concreta de que se puede contribuir a la formación y/o acumulación de capital social.

Por otra parte, esto se valida por la Reforma Urbana que vincula elementos conceptuales como espacio público, participación ciudadana e identificación de los habitantes con sus barrios, y, por otro lado, los objetivos de superación de la pobreza y mejoría de la equidad que animan al conjunto de programas de gasto social, en los que el desarrollo de comunidades integradas constituye un factor central (Arriagada y Sepúlveda, 2002).

Según Serrano (1998), la principal y quizá única forma de desarrollar y fortalecer el capital social, que es sustancial para una mejor calidad de vida, es a través de procesos de participación social; entiéndase por esto acción entre varios, la puesta en marcha de acciones en común.

Las comunidades y barrios pobres poseen un conjunto de activos intangibles y fortalezas que les da la capacidad de gestionar sus 
propios emprendimientos colectivos. Este hecho, a pesar de que suele figurar en los discursos oficiales de las agencias públicas de superación de la pobreza, es ignorado sistemáticamente en la práctica, en cuanto a su implicancia para el posible protagonismo de los beneficiarios de estos programas (Durston, 2004).

La incorporación de la participación en los Programas del MINVU representa un avance en esta materia, que da cuenta de una nueva forma de hacer política urbana, que incorpora a los actores sociales como principales agentes de cambio en el barrio, de cuya participación depende el éxito de los Programas.

Durston (1999) sostiene que las políticas públicas han contribuido más de una vez a crear capital social; y hay estudios acerca de su uso por parte del Estado para empoderar a sectores excluidos y aumentar el impacto de los servicios sociales, merced a un fuerte compromiso personal del funcionario con la comunidad local.

A partir de lo anterior, se sugieren algunas medidas para fomentar la formación de capital social de actores pobres, que incluyen apoyar las condiciones favorables para el resurgimiento del capital social, contrarrestar el clientelismo político y económico, desarrollar la capacidad de negociación estratégica de los dirigentes y facilitar el acceso de las comunidades marginadas a redes que ofrecen información y servicios (Durston, 2003).

La acción estatal debería enfocarse en políticas de creación y fortalecimiento de capital social como forma de intervención directa en la comunidad. Se indica que las instituciones comunitarias pueden ser inducidas por agentes externos mediante metodologías apropiadas, procurando una coproducción de capital social individual y familiar que se articule con las instituciones comunitarias, para lograr así el "empoderamiento" de éstas (Arriagada, 2003).

Actualmente, existen metodologías y técnicas de desarrollo de capital social que permiten crearlo a voluntad, en lugar de esperar a que surja como un subproducto de otras actividades o como un fenómeno espontáneo. La formación intencional de capital social colectivo supone expandir el radio de confianza mediante la iteración de las prácticas de cooperación y participación, hacer más complejo el sistema comunitario y realizar investigaciónacción para el emprendimiento.

El análisis de algunas experiencias realizadas en Brasil, Chile y Guatemala, permite sacar lecciones sobre la utilidad de la 
aplicación de las dimensiones de capital social a los programas de combate a la pobreza. A modo de ejemplo se encuentran las estrategias que ha aplicado el Fondo de Solidaridad e Inversión Social (FOSIS), o los programas aplicados por el INDAP en el país, para capacitar a los jóvenes o fortalecer las organizaciones productivas frente a los proveedores externos de servicios (Durston, 2002).

\section{Conclusiones}

El paradigma del capital social puede resultar un aporte significativo para el análisis de las políticas habitacionales y las políticas sociales de tipo promocional en el país, pues se enmarca en la reforma del Estado centrada en el empoderamiento de los actores sociales, y las fortalezas propias de las comunidades pobres, para superar su exclusión social. No obstante, es necesario señalar que el capital social puede constituir un recurso esencial, sólo si el Estado genera sinergia y coproducción con las comunidades, y debilita las relaciones de tipo clientelista.

Las políticas sociales integrales del país, deberían incluir la promoción del capital social en el diseño y evaluación de programas, ya que es posible potenciarlo a través de estrategias metodológicas participativas. Para ello, se requiere la intervención de políticas en el ámbito local, para favorecer y apoyar los procesos de acumulación de capital social, y de esta forma contribuir al desarrollo sustentable de los barrios pobres del país.

Promover el capital social en los barrios intervenidos por políticas habitacionales, facilitaría la formación de actores sociales empoderados en sus derechos de participación, en relación a la gestión de los programas públicos. Además, favorecería la integración a redes del sistema sociopolítico local y al fortalecimiento de sus organizaciones.

De esta forma, por una parte, las oportunidades de desarrollo que pueden presentarse en una comunidad, pueden aprovecharse de mejor manera y por otro lado, se pueden autogestionar iniciativas de desarrollo barrial basadas en las capacidades de estas comunidades y sus derechos de participación como recurso esencial en la superación de la pobreza. Sin embargo, el capital social por sí solo, no es suficiente para generar reales procesos de desarrollo; se requieren además, otros tipos de capital como el humano o económico, entre otros factores, para generar efectos positivos a largo plazo. 
Por tanto, sería importante considerar su uso por parte del Estado para empoderar a los barrios excluidos y aumentar el impacto de los servicios sociales. De esta manera, además, se puede limitar el clientelismo e incrementar la sinergia entre el Estado y sociedad civil, donde las organizaciones de base adquieren un papel central.

Sin embargo, en el ámbito de la sociedad civil, que se cruza constantemente con el plano del sistema económico, el capital social requiere apoyo e intervención externa para que su aporte potencial se haga realidad y contribuya efectivamente al desarrollo de los barrios vulnerables del país.

Esta tarea debería asumir el Ministerio de Vivienda y Urbanismo (MINVU) dentro de su intervención en las comunidades, para contribuir a la superación de la pobreza, garantizar un desarrollo local sustentable y fortalecer a los actores sociales débiles.

Los beneficios de integrar este enfoque de capital social son múltiples, quizás los nuevos programas habitacionales logren potenciar algunos componentes del capital social, pero lo fundamental es no perder de vista que un proceso de intervención urbana requiere necesariamente del sustento social que privilegie la participación de las comunidades en todas sus etapas, desde el diseño hasta la evaluación.

Por ende, resulta necesario considerar un sistema de evaluación de los programas de vivienda, desde la perspectiva del capital social, pues ofrece una mirada integral respecto al desarrollo de los barrios, entregando elementos de análisis que contribuyen a fomentar la integración social, el empoderamiento y la superación de la pobreza de los barrios vulnerables del país.

Este constituye un desafío para las actuales políticas sociales, especialmente para las políticas de vivienda, cuya efectividad ya no depende sólo del nivel de satisfacción usuaria, sino también de la medida en que se logra fortalecer a los actores sociales, se garantiza un desarrollo de barrio sustentable, se mejora la calidad de vida, a través de la inversión física y social, y por ende, se contribuye a la integración social de aquellos barrios excluidos de la sociedad.

Las potencialidades que poseen los barrios, como la confianza, cooperación, participación, redes sociales y valoración local, son componentes esenciales del capital social, que aluden a aquellos 
recursos intangibles de las comunidades, que pueden aportar a la eficacia de las políticas sociales y a un desarrollo integral de los barrios vulnerables del país.

De esta forma, se puede reemplazar el enfoque tradicional para el desarrollo de comunidades, que se centra en el análisis de los déficits de la comunidad, y se da paso a una nueva perspectiva, enfocada en la evaluación de los activos de la comunidad, siendo el capital social uno de los activos y/o fortalezas más importantes en cualquier comunidad, principalmente en aquellas que viven en situación de pobreza y exclusión social.

\section{Referencias bibliográficas}

ARRIAGADA, C.; SEPÚLVEDA, D. (2002). Satisfacción Residencial en la Vivienda Básica: La perspectiva del Capital social. División Técnica de Estudio y Fomento Habitacional. Ministerio de Vivienda y Urbanismo. Santiago de Chile.

ARRIAGADA, I. (2003). Capital Social: Potencialidades y Limitaciones Analíticas de un Concepto. Estudios Sociológicos, El Colegio de México, Septiembre-Diciembre, Vol. XXI N. 003. México.

BRAIN, I.; CUBILLOS, G. Y SABATINI, F. (2007). Integración social urbana en la nueva política habitacional. Temas de la Agenda Pública. Año 2, No 7. Vicerrectoría de Comunicaciones y Asuntos Públicos de la Pontificia Universidad Católica de Chile. Santiago de Chile.

CEPAL (2001). Capital social y políticas públicas en Chile: investigaciones recientes, Series Políticas Sociales N 55 Vol II, Santiago de Chile.

DURSTON, JOHN (2004). Capital Social Campesino y Clientelismo en Chile. CLAPSO Universidad de Texas, Austin

DURSTON, J. (2003). Superación de la Pobreza, capital social y clientelismos locales. Presentado en Seminario: Capital Social y Programas de superación de la pobreza: lineamientos para la acción. CEPAL. Santiago de Chile.

DURSTON, J. (2002), El capital social campesino en la gestión del desarrollo rural. Díadas, equipos, puentes y escaleras. Comisión Económica para América Latina y el Caribe (CEPAL). Santiago de Chile.

DURSTON, J. (2000). ¿Qué es el capital social comunitario? Santiago 
de Chile: Comisión Económica para América Latina y el Caribe (CEPAL). Serie Políticas Sociales, No. 38.

DURSTON, J. (1999). Construyendo Capital Social Comunitario: Una experiencia de empoderamiento rural en Guatemala. División de Desarrollo Social de la Comisión Económica para América Latina y el Caribe (CEPAL), Serie de Políticas Sociales 30, Santiago de Chile.

FORNI, P.; SILES, M.; BARREIRO, L. (2004). ¿Qué es el Capital Social y cómo analizarlo en contextos de Exclusión Social y Pobreza? Julian Samora Research Institute, Michigan State University.

KAZTMAN, R. (2001). Seducidos y Abandonados, conferencia regional sobre Vulnerabilidad Social, Naciones Unidas, CEPAL.

PNUD (2000). Informe de Desarrollo Humano en Chile. Más sociedad para gobernar el futuro, Programa de las Naciones Unidas para el Desarrollo, Santiago de Chile.

PUTNAM, R. (1993). “Making Democracy Work”. Princeton University Press, New Jersey.

RACZYNSKI, D. (2002). Políticas Sociales y de Superación de la Pobreza de Chile, Centro de Política Social para América Latina. Recuperado el 18 de julio de 2010. Disponible en: www.utexas.edu/colal/11/ center/claspo

SERRANO, C. (1998). Participación Social y Ciudadanía. Un debate del Chile contemporáneo. Texto preparado para la División de Estudios de MIDEPLAN. Santiago de Chile.

WORLD BANK (2000). Poverty Net, www.worldbank.org 